\title{
Історичні нариси
}

\author{
УДК 616-053.2:616.8-089(477)«1997-2012»
}

\author{
Орлов Ю.А., главный детский нейрохирург МЗ Украины, \\ Президент Украинской ассоциации детских нейрохирургов \\ Институт нейрохирургии им. акад. А.П. Ромоданова НАМН Украины, г. Киев, Украина
}

\section{Специальности «детская нейрохирургия» в Украине исполнилось 15 лет}

История развития детской нейрохирургии в Украине связана с созданием в стране в 1950 г. Киевского НИИ нейрохирургии МЗ Украины и открытием в нем первого в стране детского нейрохирургического отделения. Отделение возглавляли профессора А.П. Ромоданов (1950-1951), Ю.А. Зозуля (1952-1960), Б.А. Пельц (1960-1980), Ю.С. Бродский (1980-1989), Ю.А. Орлов (1990-2011). Сорормировано научное подразделение - отдел нейрохирургии детского возраста, бессменным руководителем которого является проф. Ю.А. Орлов. Помощь детям в регионах оказывали нейрохирурги в стационарах для взрослых. Это снижало качество помощи, а новорожденным и детям младшего возраста квалифицированную нейрохирургическую помощь оказывали только в Институте нейрохирургии. Ситуация изменилась в 1997 г., когда приказом МЗ Украины №360 («О внесении дополнений к перечню врачебных должностей в учреждениях здравоохранения») в стране введена специальность «детская нейрохирургия». Это позволило сформировать детскую нейрохирургическую службу, для чего потребовалась организация курсов специализации и повышения квалификации, которую взяли на себя кафедры нейрохирургии Национальной медицинской академии последипломного образования имени П.Л. Шупика (проф. Н.Е. Полищук) и Донецкого национального медицинского университета (профр. А.М. Кардаш). Организованы аттестация и переаттестация специалистов, открыты областные специализированные отделения в крупных областях, выделены нейрохирургические койки в детских областных больницах других областей, создана служба главных специалистов страны и областей. В Институте нейрохирургии открыты три детских отделения (церебральной нейрохирургии, руководитель - к.мед.н. А.В. Шаверский, спинальной нейрохирургии и врожденных уродств, руководитель - к.мед.н. Г.А. Кеворков, реанимации и интенсив- ной терапии, руководитель к.мед.н. Р.В. Гавриш). По состоянию на 2012 г. в Украине работают 63 детских нейрохирурга (10 - в системе НAMH Украины, 53 MЗ Украины). Ежегодно квалифицированную помощь оказывают более чем 12000 детей, из которых более 4000 - оперируют. Коечный фонд службы составляет почти 400 коек. Выполняется огромный объем консультативной помощи - более 5000 консультаций детей в год. Сравнительный анализ работы службы с момента ее создания представлен в табл. 1 .

За годы существования детской нейрохирургической службы число пролеченных детей увеличилось в 2 раза, оперированных - более чем в 3 раза, общая летальность снизилась в 3 раза, послеоперационная — на $0,7 \%$. Положительная динамика прослеживается практически по всем основным нозологическим формам поражения мозга, особенно при травме (общее снижение летальности почти в 10 раз, послеоперационной - в 8 раз). Возможности службы, ее коечного фонда практически исчерпаны. Об этом свидетельствует, с одной стороны, стабилизация показателей за последние 5 лет (табл. 2), с другой стороны, оказание помощи детям в стационарах для взрослых (табл. 3). Особенно это заметно в областях, где создание детской нейрохирургической службы не завершено (Киевская, Кировоградская, Черниговская).

Основную массу госпитализированных детей составляют пострадавшие с черепно-мозговой травмой (ЧМТ) и спинальной травмой (в 2011 г. они составили $72,9 \%$ госпитализированных). В то же время, значительной части пострадавших не оказывают специализированную помощь, особенно в сельских районах. По данным мировой статистики, частота ЧМТ в детской популяции 1-3 на 1000 . При средней частоте ЧМТ 2 на 1000 в Украине это составляет около 16000 детей, тогда как специализированную помощь оказывают 10-11 тыс. Смертность в детских

Таблица 1. Сравнительные результаты работы службы в 1998 и 2011 гг.

\begin{tabular}{|c|c|c|c|c|c|c|c|c|c|c|c|c|}
\hline \multirow{2}{*}{ Показатель } & \multicolumn{2}{|c|}{ Всего } & \multicolumn{2}{|c|}{ Травма } & \multicolumn{2}{|c|}{ Онкология } & \multicolumn{2}{|c|}{$\begin{array}{c}\text { Гидроцефа- } \\
\text { лия } \\
\end{array}$} & \multicolumn{2}{|c|}{$\begin{array}{l}\text { Уродства раз- } \\
\text { вития } \\
\end{array}$} & \multicolumn{2}{|c|}{ Другие } \\
\hline & 1998 & 2011 & 1998 & 2011 & 1998 & 2011 & 1998 & 2011 & 1998 & 2011 & 1998 & 2011 \\
\hline Лечили & 6471 & 12721 & 4610 & 9273 & 367 & 704 & 473 & 1065 & 256 & 470 & 767 & 1147 \\
\hline Оперировали & 1365 & 4596 & 603 & 3310 & 211 & 427 & 246 & 7487 & 130 & 232 & 81 & 338 \\
\hline $\begin{array}{l}\text { Хирургическая } \\
\text { активность, \% }\end{array}$ & 21,2 & 33,7 & 13,1 & 35,7 & 57,4 & 60,7 & 52,0 & 70,3 & 50,2 & 49,4 & 10,6 & 29,5 \\
\hline $\begin{array}{l}\text { Летальность } \\
\text { общая, \% }\end{array}$ & 2,9 & 0,8 & 3,1 & 0,3 & 7,4 & 4,7 & 3,2 & 2,0 & 5,9 & 4,2 & 1,7 & 1,1 \\
\hline $\begin{array}{l}\text { Летальность } \\
\text { послеопераци- } \\
\text { онная, \% }\end{array}$ & 2,5 & 1,8 & 4,2 & 0,5 & 8,4 & 7,0 & 3,6 & 2,2 & 6,3 & 6,0 & 2,1 & 2,0 \\
\hline
\end{tabular}


Таблица 2. Динамика показателей работы детской нейрохирургической службы Украины за последние 5 лет.

\begin{tabular}{|l|c|c|c|c|c|}
\hline \multirow{2}{*}{\multicolumn{1}{|c|}{ Показатель }} & \multicolumn{5}{|c|}{ Величина показателя по годам } \\
\cline { 2 - 6 } & $\mathbf{2 0 0 7}$ & $\mathbf{2 0 0 8}$ & $\mathbf{2 0 0 9}$ & $\mathbf{2 0 1 0}$ & $\mathbf{2 0 1 1}$ \\
\hline Лечили & 12519 & 13137 & 12188 & 12685 & 12721 \\
\hline Оперировали & 4491 & 4489 & 4019 & 4476 & 4596 \\
\hline $\begin{array}{l}\text { Хирургическая актив- } \\
\text { ность, \% }\end{array}$ & 35,9 & 34,2 & 33,0 & 35,3 & 35,7 \\
\hline Общая летальность, \% & 0,9 & 0,9 & 0,9 & 0,9 & 0,9 \\
\hline $\begin{array}{l}\text { Послеоперационная ле- } \\
\text { тальность, \% }\end{array}$ & 1,8 & 1,8 & 2,0 & 1,7 & 1,8 \\
\hline
\end{tabular}

Таблица 3. Объем оказания нейрохирургической помощи в детских и взрослых стационарах в 2011 г.

\begin{tabular}{|l|c|c|c|c|c|c|}
\hline \multicolumn{1}{|c|}{ Лечили детей } & Всего & Травма & $\begin{array}{c}\text { Гидроце- } \\
\text { ралия }\end{array}$ & Онкология & $\begin{array}{c}\text { Уродства } \\
\text { развития }\end{array}$ & Другие \\
\hline $\begin{array}{l}\text { В детских } \\
\text { стационарах }\end{array}$ & 12721 & 9273 & 1065 & 704 & 470 & 1147 \\
\hline $\begin{array}{l}\text { В стационарах } \\
\text { для взрослых }\end{array}$ & 1784 & 1426 & 47 & 33 & 21 & 257 \\
\hline Итого... & 14505 & 10699 & 1112 & 737 & 491 & 1404 \\
\hline
\end{tabular}

специализированных стационарах соответствует лучшим мировым показателям и не превышает 0,3\%. При тяжелой ЧМТ, оказании помощи в неспециализированных стационарах, где отсутствует современное техническое оснащение (КТ, МРТ, УЗИ), летальность увеличивается в $2-3$ раза!

В связи с созданием специальности «детская нейрохирургия» появились новые тенденции и направления, о которых ранее даже не задумывались. Речь идет об участии детских нейрохирургов в пренатальной диагностике поражения нервной системы плода, планировании характера родоразрешения, а также новом направлении в детской нейрохирургии - неонатальной нейрохирургии или нейрохирургии новорожденных.

Нейрохирургическая помощь новорожденным чаще неотложная, по жизненным показаниям. Это касается родовой травмы, периинтравентрикулярного кровоизлияния (ПИВК) III-IV степени, спинномозговой грыжи, осложненной ликвореей, нейрорахишизиса. Число новорожденных, у которых выявляют ПИВК, требующее нейрохирургической помощи, ежегодно превышает 1000 наблюдений и имеет тенденцию к увеличению. Это обусловлено увеличением числа рожденных преждевременно с малой массой тела, у которых частота ПИВК обратно пропорциональна массе тела (у доношенных новорожденных - 10\%, при гестации до 32 нед и массе тела до 1500 г - 80\%, до 1000 г - 100\%). Операции у новорожденных с малой массой тела, особенно критической, сопряжены с большими сложностями выхаживания их после операций, необходимостью применения искусственной вентиляции легких, поддержания температурного режима, проведения парентерального питания. В то же время, оказание ранней нейрохирургической помощи позволяет сохранить жизнь этих детей, уменьшить частоту выполнения в последующем ликворошунтирующих операций, инвалидность.

Другим аспектом неотложной нейрохирургической помощи новорожденным являются врожденные уродства (спинномозговая грыжа, осложненная ликвореей, нейрорахишизис). Внедрение протоколов оказания нейрохирургической помощи при врожденных уродствах развития нервной системы с выполнением операций при разрыве грыжи в первые 24 ч, а при ее угрозе - в первые 72 ч жизни обеспечило снижение летальности в 10 раз. Новым направлением является дородовая диагностика патологии и перевод неотложных операций в неотложно-плановые. При планировании сроков родоразрешения одновременно планируют и сроки нейрохирургического вмешательства. Кроме того, дородовая диагностика и планирование сроков операции позволили создать новые подходы к возмещению кровопотери. Имеется в виду заготовка и использование при этих операциях плацентарной крови, характеризующейся полной совместимостью, повышенной способностью к насыщению кислородом и большим запасом мезенхимальных клеток, способствующих репаративным процессам.

В 2009 г. создана Украинская ассоциация детских нейрохирургов. Детские нейрохирурги стали активными участниками Европейской и Всемирной ассоциаций нейрохирургов и детских нейрохирургов. Это позволило детским нейрохирургам Украины поддерживать контакты с учеными других стран, участвовать в международных съездах и конференциях, повышать свой уровень подготовки в школах и семинарах. Одновременно детские нейрохирурги не теряют связи со своими коллегами, оказывающими специализированную помощь взрослым. Они, как правило, являются и членами Украинской ассоциации нейрохирургов, участвуют в совместных конференциях и совещаниях.

Таким образом, детская нейрохирургическая служба страны встречает свое 15-летие как сорормировавшаяся специальность, имеющая определенные достижения, новые планы совершенствования качества помощи детям, хотя и существует много проблемных вопросов, требующих решения 